\title{
A Metabolomic Strategy to Screen the Prototype Components and Metabolites of Shuang-Huang-Lian Injection in Human Serum by Ultra Performance Liquid Chromatography Coupled with Quadrupole Time-of-Flight Mass Spectrometry
}

\author{
Mingxing Guo, ${ }_{1}^{1}$ Baosheng Zhao, ${ }^{1}$ Haiyu Liu, ${ }^{1}$ Li Zhang, ${ }^{1}$ Long Peng, ${ }^{1}$ Lingling Qin, \\ Zhixin Zhang, ${ }^{1}$ Jian Li, ${ }^{2}$ Chengke Cai, ${ }^{3}$ and Xiaoyan Gao ${ }^{1}$ \\ ${ }^{1}$ Science Experiment Center for Traditional Chinese Medicine, Beijing University of Chinese Medicine, \\ No. 11, North Third Ring Road, Chaoyang District, Beijing 100029, China \\ ${ }^{2}$ School of Basic Medical Sciences, Beijing University of Chinese Medicine, No. 11, North Third Ring Road, \\ Chaoyang District, Beijing 100029, China \\ ${ }^{3}$ School of Chinese Material Medica, Beijing University of Chinese Medicine, South of Wangjing Middle Ring Road, \\ Chaoyang District, Beijing, 100102, China
}

Correspondence should be addressed to Chengke Cai; cck98@126.com and Xiaoyan Gao; gaoxiaoyan0913@sina.com

Received 22 December 2013; Accepted 19 January 2014; Published 26 February 2014

Academic Editor: Ying-Yong Zhao

Copyright (c) 2014 Mingxing Guo et al. This is an open access article distributed under the Creative Commons Attribution License, which permits unrestricted use, distribution, and reproduction in any medium, provided the original work is properly cited.

Shuang-huang-lian injection (SHLI) is a famous Chinese patent medicine, which has been wildly used in clinic to treat acute respiratory tract infection, pneumonia, influenza, and so forth. Despite the widespread clinical application, the prototype components and metabolites of SHLI have not been fully elucidated, especially in human body. To discover and screen the constituents or metabolites of Chinese medicine in biofluids tends to be more and more difficult due to the complexity of chemical compositions, metabolic reactions and matrix effects. In this work, a metabolomic strategy to comprehensively elucidate the prototype components and metabolites of SHLI in human serum conducted by UPLC-Q-TOF/MS was developed. Orthogonal partial least squared discriminant analysis (OPLS-DA) was applied to distinguish the exogenous, namely, druginduced constituents, from endogenous in human serum. In the S-plot, 35 drug-induced constituents were found, including 23 prototype compounds and 12 metabolites which indicated that SHLI in human body mainly caused phase II metabolite reactions. It was concluded that the metabolomic strategy for identification of herbal constituents and metabolites in biological samples was successfully developed. This identification and structural elucidation of the chemical compounds provided essential data for further pharmacological and pharmacokinetics study of SHLI.

\section{Introduction}

Shuang-huang-lian injection (SHLI) is a typical Chinese herbal injection that is made from the extracts of Flos Lonicerae Japonicae, Radix Scutellariae, and Fructus Forsythiae. It has been widely used for the treatment of acute upper respiratory tract infections $[1,2]$. Baicalin, chlorogenic acid, and forsythin are the marker compounds representing Radix Scutellariae, Flos Lonicerae Japonicae, and Fructus Forsythiae, respectively, for the quality control of this medicine [3]. Though several published papers have reported the determination of major active components and metabolites in Shuang-huang-lian (SHL) preparations [4-6], there is no substantial evidence to confirm the holistic existing form of SHLI in vivo, especially in human body. Therefore, systematically, screening the constituents and metabolites of SHLI in human blood is of great significance for interpreting its material basis for pharmacological effects. Currently, the ingredients of SHL formula have been detected in rat blood [7]. However, the recent study suggests that 
species differences in key hepatic efflux transporters are sufficiently profound to warrant careful re-examination of conclusions and to design future studies with caution [8]. Some data have revealed that rat liver contains much more $(\sim 10$-fold $)$ apical multidrug resistance-associated protein 2 (Mrp2) resulting in a much higher capacity for the biliary excretion of organic anions in rats than human or other preclinical species [9]. Therefore, to reveal the pharmacological mechanism of SHLI, comprehensive analysis of the constituents and metabolites in human body is more scientific and rational.

The process of metabolite detection and identification is typically a labor-intensive and time-consuming process. This process has been simplified by the use of radiolabeled compounds and/or spectroscopic techniques such as mass spectrometry and NMR spectroscopy [10-13]. Of these analysis techniques, liquid chromatography coupled with electrospray ionization mass spectrometer has been widely used to detect and identify trace levels of drugs and metabolites in various biological samples due to its high sensitivity and selectivity [14-16]. Ultra performance liquid chromatography (UPLC) applied for short run times combined with a quadrupole/time of flight-mass spectrometer (Q/TOF-MS) which offers high mass accuracy has become a major tool that provides a significant source of global constituent and metabolite profiling data [17-19]. Given the chemical complexity of SHLI in vivo, UPLC-Q-TOF/MS provides faster separations for complex blood samples and valuable structural insights into the characterization of SHLI metabolites.

A straightforward approach for identifying exogenous metabolites in vivo is to compare the LC-MS chromatograms of biological samples collected before and after xenobiotic treatment. However, without using effective analysis method, it is difficult to identify exogenous metabolites through visual examination of LC-MS chromatograms that contain information from thousands of chemical species [20]. A metabolomic strategy has been developed to handle the acquired data and to search for the discriminating features from biosample sets. A xenobiotic and its metabolites only appear in the samples after xenobiotic treatment, and so when using metabolomic strategy, the differences between the control group and the xenobiotic-treated group are mainly defined by the presence of the xenobiotic and its metabolites. With appropriate data processing, the separation of the control group and the xenobiotic-treated group can be achieved in the score plot of a multivariate model, and exogenous metabolites can be conveniently identified by analyzing ions contributing to the separation of the two groups. Employing this approach, the present study aims to develop a metabolomic strategy to comprehensively elucidate the prototype components and metabolites of SHLI in human serum conducted by UPLCQ-TOF/MS.

\section{Experiment}

2.1. Materials. SHLI was achieved from the Second Chinese Medicine Factory of Harbin Pharm. Group CO., Ltd. (No.
1204014). HPLC grade formic acid was obtained from Sigma Chemical Co., Ltd. (St. Louis, MO, USA). Methanol (HPLC grade) was acquired from Fisher Corporation (Michigan, USA). Water was purified with a Milli-Q system (Millipore, Bedford, USA).

2.2. Subjects and Clinical Trial Design. The study was approved by an independent ethics committee at Beijing University of Chinese Medicine, before recruitment commenced. Before the initiation of study procedures, all volunteers gave their written informed consent for participation in the study. Thirteen healthy volunteers, without taking any medication, participated in the study. They were aged between 25 and 40 years and with weight between 50 and $80 \mathrm{~kg}$. After overnight fasting, early-morning blood samples (20 mL each) were collected from the medial cubital vein into evacuated tubes and marked as the control group ( $\mathrm{C}$ group). Then participants were intravenous infusion of $60 \mathrm{mg} / \mathrm{kg}$ of SHLI (dissolved with $500 \mathrm{~mL}$ saline solution). The blood samples were collected at $0.5 \mathrm{~h}$ after $S H L I$ administration and marked as SHLI dosed group (SHLI group). The blood supernatant was allowed to clot overnight at room temperature, and the clotted material was removed by centrifugation $(3000 \mathrm{rpm}$, $15 \mathrm{~min})$. The serum was collected and stored at $-80^{\circ} \mathrm{C}$.

2.3. Pretreatment Procedure for SHLI. The Shuang-huanglian lyophilized powder for injection $(0.1 \mathrm{~g})$ was weighed and dissolved with $100 \mathrm{~mL}$ water. Then, it was filtered by a $0.22 \mu \mathrm{m}$ filter before UPLC-Q-TOF/MS analysis.

2.4. Pretreatment Procedure for Serum Samples. All serum samples were thawed at room temperature followed by methanol protein precipitation. Serum $(200 \mu \mathrm{L})$ was added with $600 \mu \mathrm{L}$ methanol, vortexed for $30 \mathrm{~s}$, and centrifuged at $14000 \mathrm{~g}$ for $10 \mathrm{~min}$ at $4^{\circ} \mathrm{C}$. Then, supernatant $(400 \mu \mathrm{L})$ was transferred to a clean tube and evaporated to dryness under a gentle stream of nitrogen. The residue was redissolved with $100 \mu \mathrm{L}$ ultra high purity water and transferred to an autosampler vial.

2.5. UPLC-Q-TOF/MS Analysis. Separation and detection of the components and metabolites of SHLI were performed on a Waters Acquit UPLC chromatographic system (Waters Corp., Milford, USA) equipped with a Evoe G2 Q/TOF (Waters MS Technologies, Manchester, UK). An electrospray ionization source (ESI) interface was used in both positive and negative ion modes. Acquit UPLC HSS T3 column $(2.1 \mathrm{~mm} \times 100 \mathrm{~mm}, 1.8 \mu \mathrm{m}$, Waters, UK) was applied for all analyses. The mobile phase was composed of $\mathrm{A}(0.1 \%$ formic acid in water) and $B$ (methanol) with a linear gradient elution: $0-1 \mathrm{~min}$, maintained at $0 \% \mathrm{~B} ; 1-5 \mathrm{~min}$, from $0 \% \mathrm{~B}$ to $40 \% \mathrm{~B}$; $5-8 \mathrm{~min}$, from $40 \% \mathrm{~B}$ to $100 \% \mathrm{~B} ; 8-13 \mathrm{~min}$, maintained at $0 \%$ $\mathrm{B}$; $13.0-13.1 \mathrm{~min}$, isocratic of $0 \% \mathrm{~B} ; 13.1-15 \mathrm{~min}$, maintained at $0 \% \mathrm{~B}$. The flow rate was $0.30 \mathrm{~L} / \mathrm{min}$. The analytic column and autosampler were maintained at temperatures of $45^{\circ} \mathrm{C}$ and $4^{\circ} \mathrm{C}$, respectively. Then, $1 \mu \mathrm{L}$ of sample solution was injected for each run. Data were collected from $\mathrm{m} / z 50$ to $\mathrm{m} / z 1200$. For positive ion mode, the capillary and cone voltage were 

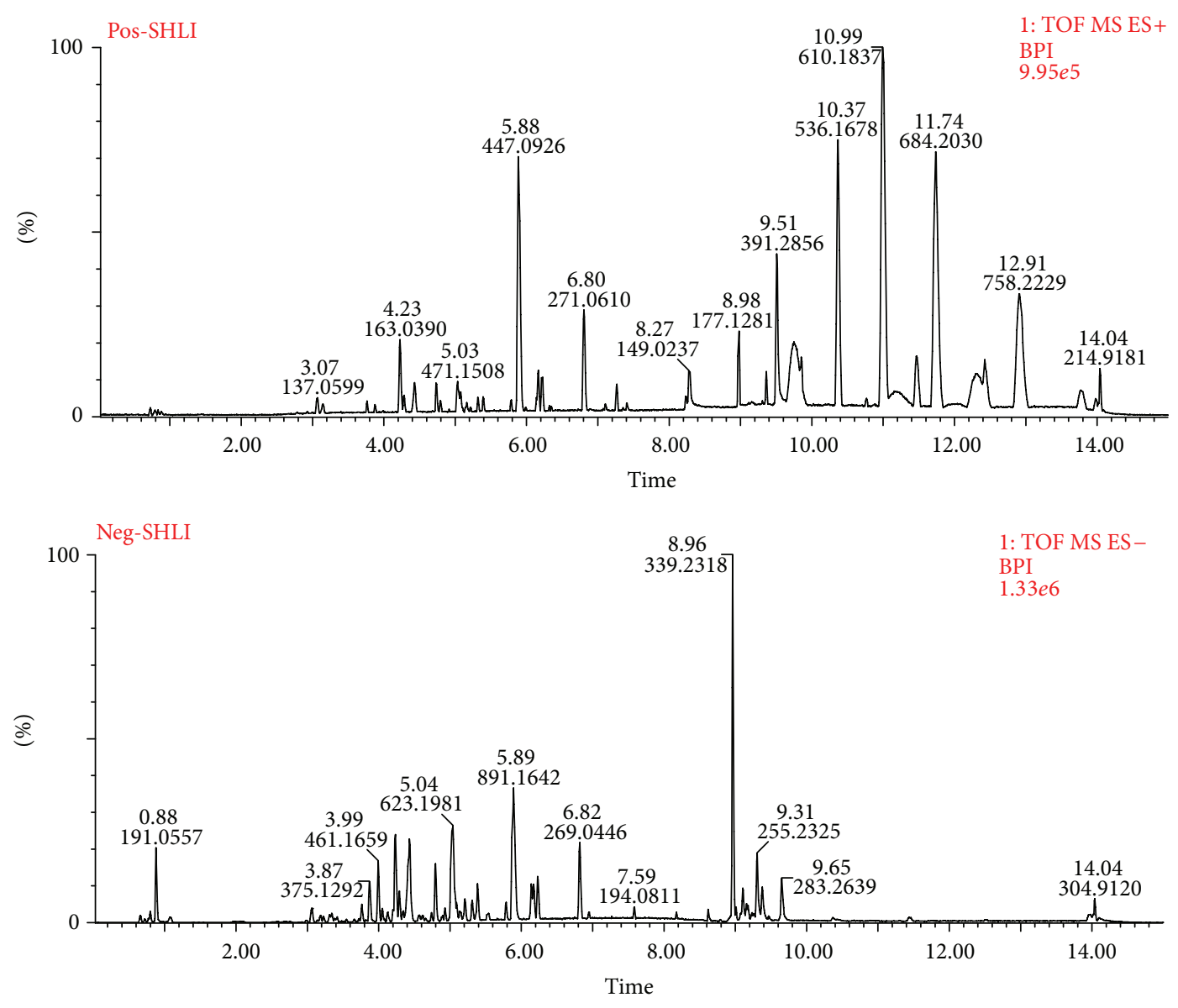

FIGURE 1: UPLC-Q-TOF/MS BPI chromatograms of SHLI in positive ion mode and negative ion mode.

set at $3 \mathrm{kV}$ and $35 \mathrm{~V}$. For negative ion mode, the capillary and cone voltage were set at $2.5 \mathrm{kV}$ and $35 \mathrm{~V}$. The conservation gas was set at $700 \mathrm{~L} / \mathrm{h}$ at a temperature of $350^{\circ} \mathrm{C}$. The source temperature was set at $100^{\circ} \mathrm{C}$. The cone gas was set at $50 \mathrm{~L} / \mathrm{h}$. Leucine-enkephalin was used as the lock mass solution to ensure the accuracy and reproducibility.

2.6. Data Processing and Statistical Analysis. The ES+ and ES- raw data was analyzed by MarkerLynx XS software (Waters Corp., Milford, USA). For extracting data from the raw file and detecting potential markers, the retention time range was set at $0-13 \mathrm{~min}$, the mass range at 50-1000 amu, and the mass tolerance as 0.01 . For detecting chromatographic peaks in the Apex Track Peak, peak width at 5\% height was set at 1.00, and the peak-to-peak baseline noise was 0.00 . For collecting parameters, the marker intensity threshold was set at $1000 \mathrm{cps}$, the mass window was $0.02 \mathrm{amu}$, and retention time window was $0.20 \mathrm{~min}$. The noise elimination level was 6. This process provided alignment of drift (retention time and accurate mass) in data and ensured that a chromatographic peak was identified with the same parameters in each sample. Subsequently, a list of intensities or peak areas of the peaks was then generated for the first chromatogram, using the ER- $m / z$ pairs as identifiers. The procedure was applied for each UPLC/MS analysis. The ion intensities or peak area for each peak detected was also normalized within each sample to the sum of the peak intensities in that sample. The three-dimensional data were introduced into the EZinfo 2.0 software (Waters Corporation, Milford, MA, USA) for orthogonal partial least-squares-discriminate analysis (OPLS-DA).

\section{Results and Discussion}

3.1. Identification and Analysis of Chemical Components in SHLI. Global profiling of both positive and negative ion modes was analyzed by UPLC-Q-TOF/MS. The typical base peak intensity (BPI) chromatograms (positive ion mode and negative ion mode) of SHLI were shown in Figure 1. In total, 38 constituents were detected and tentatively characterized in SHLI (Table 1). $\mathrm{MS}^{\mathrm{E}}$ technique, a new technique used in deducing the splitting disciplinary of MS, was applied to data collection. $\mathrm{MS}^{\mathrm{E}}$ technique could provide parallel alternating scans for acquisition at low collision energy to obtain precursor ion information or at a ramping of high collision energy to obtain a full-scan accurate mass of fragments, precursor ions, and neutral loss information $[21,22]$. Here, the high precision MS/MS fragments 
TABLE 1: UPLC-Q-TOF/MS identification of the constituents in SHLI.

\begin{tabular}{|c|c|c|c|c|c|c|c|c|}
\hline NO. & $t_{R}(\min )$ & $\begin{array}{l}\text { Positive } \\
\text { ion MS }\end{array}$ & $\begin{array}{l}\text { Negative } \\
\text { ion MS }\end{array}$ & Formula & Identification & $\begin{array}{c}\text { Positive ion } \\
\text { MS/MS }\end{array}$ & $\begin{array}{l}\text { Negative ion } \\
\text { MS/MS }\end{array}$ & Class \\
\hline 1 & 0.88 & 193.0722 & 191.0557 & $\mathrm{C}_{7} \mathrm{H}_{12} \mathrm{O}_{6}$ & Quinic acid & 112.0521 & $\begin{array}{c}127.0400 \\
85.0288\end{array}$ & Quinic acid \\
\hline 2 & 3.77 & 355.1033 & 353.0873 & $\mathrm{C}_{16} \mathrm{H}_{18} \mathrm{O}_{9}$ & Chlorogenic acid & $\begin{array}{l}163.0395 \\
145.0279 \\
135.0454\end{array}$ & $\begin{array}{l}191.0549 \\
179.0341 \\
135.0449\end{array}$ & Quinic acid \\
\hline 3 & 3.87 & - & 375.1287 & $\mathrm{C}_{16} \mathrm{H}_{24} \mathrm{O}_{10}$ & $\begin{array}{l}\text { Isomer of loganic } \\
\text { acid }\end{array}$ & - & $\begin{array}{l}213.0765 \\
169.0867 \\
151.0759\end{array}$ & Iridoid \\
\hline 4 & 3.90 & 623.2080 & - & $\mathrm{C}_{29} \mathrm{H}_{34} \mathrm{O}_{15}$ & $\begin{array}{c}\text { Isomer of } \\
\text { suspensaside A }\end{array}$ & $\begin{array}{l}191.0568 \\
149.0232\end{array}$ & $\begin{array}{l}461.1674 \\
443.1554 \\
205.0319\end{array}$ & $\begin{array}{l}\text { Phenylethanoid } \\
\text { glycoside }\end{array}$ \\
\hline 5 & 3.97 & - & 461.1659 & $\mathrm{C}_{20} \mathrm{H}_{30} \mathrm{O}_{12}$ & Forsythoside E & - & $\begin{array}{l}315.1076 \\
205.0718 \\
135.0448\end{array}$ & $\begin{array}{l}\text { Phenylethanoid } \\
\text { glycoside }\end{array}$ \\
\hline 6 & 4.20 & - & 375.1287 & $\mathrm{C}_{16} \mathrm{H}_{24} \mathrm{O}_{10}$ & Loganic acid & - & $\begin{array}{l}213.0778 \\
169.0853 \\
151.0773\end{array}$ & Iridoid \\
\hline 7 & 4.24 & 355.1023 & 353.0866 & $\mathrm{C}_{16} \mathrm{H}_{18} \mathrm{O}_{9}$ & $\begin{array}{l}\text { 3-O- } \\
\text { Caffeoylquinic } \\
\text { acid }\end{array}$ & $\begin{array}{l}163.0393 \\
145.0286\end{array}$ & $\begin{array}{l}191.0569 \\
179.0365\end{array}$ & Quinic acid \\
\hline 8 & 4.29 & - & 353.0873 & $\mathrm{C}_{16} \mathrm{H}_{18} \mathrm{O}_{9}$ & $\begin{array}{l}\text { 4-O- } \\
\text { Caffeoylquinic } \\
\text { acid }\end{array}$ & - & $\begin{array}{l}173.0450 \\
135.0453\end{array}$ & Quinic acid \\
\hline 9 & 4.35 & - & 639.1925 & $\mathrm{C}_{29} \mathrm{H}_{36} \mathrm{O}_{16}$ & Suspensaside & - & $\begin{array}{l}621.1841 \\
469.1273\end{array}$ & $\begin{array}{l}\text { Phenylethanoid } \\
\text { glycoside }\end{array}$ \\
\hline 10 & 4.43 & 375.1288 & 373.1129 & $\mathrm{C}_{16} \mathrm{H}_{22} \mathrm{O}_{10}$ & Secologanic acid & $\begin{array}{l}213.0749 \\
195.0638\end{array}$ & $\begin{array}{l}193.0494 \\
149.0605\end{array}$ & Iridoid \\
\hline 11 & 4.45 & 391.1255 & 389.1074 & $\mathrm{C}_{16} \mathrm{H}_{22} \mathrm{O}_{11}$ & Monotropein & $\begin{array}{l}211.0586 \\
177.0546 \\
151.0395\end{array}$ & $\begin{array}{l}209.0455 \\
165.0554 \\
149.0605\end{array}$ & Iridoid \\
\hline 12 & 4.58 & - & 639.1918 & $\mathrm{C}_{29} \mathrm{H}_{36} \mathrm{O}_{16}$ & $\begin{array}{c}\text { Isomer of } \\
\text { suspensaside }\end{array}$ & - & $\begin{array}{l}445.1318 \\
205.0318 \\
179.0346\end{array}$ & $\begin{array}{l}\text { Phenylethanoid } \\
\text { glycoside }\end{array}$ \\
\hline 13 & 4.72 & - & 403.1239 & $\mathrm{C}_{17} \mathrm{H}_{24} \mathrm{O}_{11}$ & $\begin{array}{c}\text { Isomer of } \\
\text { secoxyloganin }\end{array}$ & - & 241.1177 & Iridoid \\
\hline 14 & 4.73 & 359.1348 & - & $\mathrm{C}_{16} \mathrm{H}_{22} \mathrm{O}_{9}$ & Sweroside & $\begin{array}{r}197.0812 \\
151.0400\end{array}$ & - & Iridoid \\
\hline 15 & 4.80 & 625.2124 & 623.1982 & $\mathrm{C}_{29} \mathrm{H}_{36} \mathrm{O}_{15}$ & Acteoside & $\begin{array}{l}471.1504 \\
325.0927 \\
163.0398\end{array}$ & $\begin{array}{l}461.1671 \\
443.1567 \\
203.0428\end{array}$ & $\begin{array}{l}\text { Phenylethanoid } \\
\text { glycoside }\end{array}$ \\
\hline 16 & 4.89 & - & 755.2399 & $\mathrm{C}_{34} \mathrm{H}_{44} \mathrm{O}_{19}$ & Forsythoside B & - & $\begin{array}{l}593.2103 \\
447.1500 \\
315.1137\end{array}$ & $\begin{array}{l}\text { Phenylethanoid } \\
\text { glycoside }\end{array}$ \\
\hline 17 & 4.93 & 623.1986 & 621.1816 & $\mathrm{C}_{29} \mathrm{H}_{34} \mathrm{O}_{15}$ & Suspensaside A & $\begin{array}{l}191.0571 \\
149.0234\end{array}$ & $\begin{array}{l}487.1371 \\
469.1180\end{array}$ & $\begin{array}{l}\text { Phenylethanoid } \\
\text { glycoside }\end{array}$ \\
\hline 18 & 5.03 & 625.2133 & 623.1970 & $\mathrm{C}_{29} \mathrm{H}_{36} \mathrm{O}_{15}$ & Forsythoside A & $\begin{array}{l}471.1512 \\
325.0919 \\
163.0398\end{array}$ & $\begin{array}{l}461.1671 \\
443.1567 \\
205.0321\end{array}$ & $\begin{array}{l}\text { Phenylethanoid } \\
\text { glycoside }\end{array}$ \\
\hline 19 & 5.06 & 405.1387 & 403.1236 & $\mathrm{C}_{17} \mathrm{H}_{24} \mathrm{O}_{11}$ & Secoxyloganin & $\begin{array}{c}243.0880 \\
211.0612\end{array}$ & $\begin{array}{l}371.0979 \\
223.0611\end{array}$ & Iridoid \\
\hline 20 & 5.09 & - & 515.1174 & $\mathrm{C}_{25} \mathrm{H}_{24} \mathrm{O}_{12}$ & $\begin{array}{c}3,4- \\
\text { Dicaffeoylquinic } \\
\text { acid }\end{array}$ & - & $\begin{array}{c}353.0906 \\
191.0561 \\
135.0446\end{array}$ & Quinic acid \\
\hline 21 & 5.13 & - & 515.1174 & $\mathrm{C}_{25} \mathrm{H}_{24} \mathrm{O}_{12}$ & $\begin{array}{c}3,5- \\
\text { Dicaffeoylquinic } \\
\text { acid }\end{array}$ & - & $\begin{array}{l}353.0906 \\
173.0355 \\
135.0446 \\
\end{array}$ & Quinic acid \\
\hline
\end{tabular}


TABle 1: Continued.

\begin{tabular}{|c|c|c|c|c|c|c|c|c|}
\hline NO. & $t_{R}(\min )$ & $\begin{array}{l}\text { Positive } \\
\text { ion MS }\end{array}$ & $\begin{array}{c}\text { Negative } \\
\text { ion MS }\end{array}$ & Formula & Identification & $\begin{array}{c}\text { Positive ion } \\
\text { MS/MS }\end{array}$ & $\begin{array}{c}\text { Negative ion } \\
\text { MS/MS }\end{array}$ & Class \\
\hline 22 & 5.21 & - & 519.1863 & $\mathrm{C}_{26} \mathrm{H}_{32} \mathrm{O}_{11}$ & $\begin{array}{l}\text { Pinoresinol } \\
\text { 4-O-glucoside }\end{array}$ & - & $\begin{array}{l}357.1336 \\
151.0398 \\
136.0164\end{array}$ & Lignan \\
\hline 23 & 5.30 & 463.0876 & 461.0730 & $\mathrm{C}_{21} \mathrm{H}_{18} \mathrm{O}_{12}$ & $\begin{array}{c}\text { Luteolin } \\
\text { 7-galacturonide }\end{array}$ & $\begin{array}{l}287.0552 \\
269.0462 \\
241.0493\end{array}$ & $\begin{array}{l}285.0399 \\
211.0400 \\
113.0238\end{array}$ & Flavonoid \\
\hline 24 & 5.32 & - & 447.0927 & $\mathrm{C}_{21} \mathrm{H}_{20} \mathrm{O}_{11}$ & $\begin{array}{l}\text { 5,6-Dihydroxy } \\
\text { flavanone-7-O- } \\
\text { glucuronide }\end{array}$ & - & $\begin{array}{l}285.0399 \\
267.0309 \\
239.0356\end{array}$ & Flavonoid \\
\hline 25 & 5.35 & - & 621.1788 & $\mathrm{C}_{29} \mathrm{H}_{34} \mathrm{O}_{15}$ & Suspensaside A & - & $\begin{array}{l}487.1510 \\
179.0351\end{array}$ & $\begin{array}{l}\text { Phenylethanoid } \\
\text { glycoside }\end{array}$ \\
\hline 26 & 5.37 & 611.1599 & 609.1453 & $\mathrm{C}_{27} \mathrm{H}_{30} \mathrm{O}_{16}$ & Rutin & $\begin{array}{l}465.1016 \\
303.1489\end{array}$ & $\begin{array}{l}300.0253 \\
271.0236 \\
255.0290\end{array}$ & Flavonoid \\
\hline 27 & 5.38 & 517.1344 & 515.1186 & $\mathrm{C}_{25} \mathrm{H}_{24} \mathrm{O}_{12}$ & $\begin{array}{l}4,5- \\
\text { Dicaffeoylquinic } \\
\text { acid }\end{array}$ & $\begin{array}{l}499.1206 \\
355.1702 \\
337.0856\end{array}$ & $\begin{array}{c}353.0866 \\
191.0553 \\
173.0451\end{array}$ & Quinic acid \\
\hline 28 & 5.54 & - & 757.2550 & $\mathrm{C}_{34} \mathrm{H}_{46} \mathrm{O}_{19}$ & Centauroside & - & $\begin{array}{l}525.1569 \\
493.1695 \\
179.0511\end{array}$ & Iridoid \\
\hline 29 & 5.78 & - & 533.2020 & $\mathrm{C}_{27} \mathrm{H}_{34} \mathrm{O}_{11}$ & Phillyrin & - & $\begin{array}{l}371.1484 \\
356.1257 \\
121.0295\end{array}$ & Lignan \\
\hline 30 & 5.88 & 447.0925 & 445.0771 & $\mathrm{C}_{21} \mathrm{H}_{18} \mathrm{O}_{11}$ & Baicalin & 271.0603 & $\begin{array}{l}269.0455 \\
241.0503\end{array}$ & Flavonoid \\
\hline 31 & 6.01 & 477.1027 & 475.0876 & $\mathrm{C}_{22} \mathrm{H}_{19} \mathrm{O}_{12}$ & $\begin{array}{c}5,2^{\prime} \text {-Dihydroxy- } \\
6^{\prime}- \\
\text { methoxyflavone- } \\
\text { 7-O-glucuronide }\end{array}$ & 301.0713 & $\begin{array}{l}443.0556 \\
299.0546\end{array}$ & Flavonoid \\
\hline 32 & 6.17 & 431.0978 & 429.0815 & $\mathrm{C}_{21} \mathrm{H}_{18} \mathrm{O}_{10}$ & $\begin{array}{c}\text { Chrysin } \\
\text { 7-glucuronide }\end{array}$ & 255.0658 & 253.0505 & Flavonoid \\
\hline 33 & 6.23 & 461.1079 & 459.0927 & $\mathrm{C}_{22} \mathrm{H}_{20} \mathrm{O}_{11}$ & Wogonoside & $\begin{array}{l}285.0767 \\
270.0534\end{array}$ & $\begin{array}{l}283.0611 \\
268.0375 \\
239.0345\end{array}$ & Flavonoid \\
\hline 34 & 6.38 & - & 445.0779 & $\mathrm{C}_{21} \mathrm{H}_{18} \mathrm{O}_{11}$ & $\begin{array}{l}\text { Norwogonin-7- } \\
\text { O-glucuronide }\end{array}$ & - & 269.0422 & Flavonoid \\
\hline 35 & 6.81 & 271.0608 & 269.0446 & $\mathrm{C}_{15} \mathrm{H}_{10} \mathrm{O}_{5}$ & Baicalein & $\begin{array}{l}271.0623 \\
253.0498 \\
123.0083\end{array}$ & $\begin{array}{l}251.0362 \\
223.0379 \\
195.0447\end{array}$ & Flavonoid \\
\hline 36 & 7.26 & 285.0761 & 283.0602 & $\mathrm{C}_{16} \mathrm{H}_{12} \mathrm{O}_{5}$ & Wogonin & 270.0489 & $\begin{array}{l}268.0377 \\
162.9845\end{array}$ & Flavonoid \\
\hline 37 & 7.35 & 255.0654 & - & $\mathrm{C}_{15} \mathrm{H}_{10} \mathrm{O}_{4}$ & Chrysin & 153.0173 & - & Flavonoid \\
\hline 38 & 7.40 & 285.0762 & 283.0601 & $\mathrm{C}_{16} \mathrm{H}_{12} \mathrm{O}_{5}$ & $\begin{array}{l}\text { Isomer of } \\
\text { wogonin }\end{array}$ & 270.0489 & 268.0409 & Flavonoid \\
\hline
\end{tabular}

information obtained from the $M S^{\mathrm{E}}$ technique were also listed in Table 1 to explain the structure information of the chemical constituents. All the constituents and the fragmentation information were consistent with previous reports $[23,24]$.

3.2. Analysis of Human Serum by Metabolomic Strategy. Figure 2 represented the typical BPI chromatograms (positive ion mode and negative ion mode) of human serum samples before and after $S H L I$ administration. The prototype components and metabolites of SHLI in human serum were almost submerged by the endogenous metabolites due to the high level of endogenous signals. Interferences from biological matrices remain a major challenge to detection of metabolites in vivo. Without the presence of a radiolabeled isotope or a data-mining tool, it would be almost impossible to identify low level exogenous metabolites. In our work, a metabolomic strategy was employed to phenotype the differences between $\mathrm{C}$ group and SHLI group. The LC/MS 
TABLE 2: The prototype components and metabolites in human serum after SHLI dosed in both positive and negative mode.

\begin{tabular}{|c|c|c|c|c|c|c|c|c|}
\hline NO. & $t_{R}(\min )$ & $\begin{array}{l}\text { Positive } \\
\text { ion MS }\end{array}$ & $\begin{array}{l}\text { Negative } \\
\text { ion MS }\end{array}$ & Formula & Identification & $\begin{array}{l}\text { Positive } \\
\text { ion } \\
\text { MS/MS }\end{array}$ & $\begin{array}{l}\text { Negative } \\
\text { ion } \\
\text { MS/MS }\end{array}$ & Relegation \\
\hline 1 & 0.88 & 193.0722 & 191.0557 & $\mathrm{C}_{7} \mathrm{H}_{12} \mathrm{O}_{6}$ & Quinic acid & 112.0521 & $\begin{array}{c}127.0400 \\
85.0288\end{array}$ & Prototype component \\
\hline 2 & 3.77 & 355.1033 & 353.0873 & $\mathrm{C}_{16} \mathrm{H}_{18} \mathrm{O}_{9}$ & Chlorogenic acid & $\begin{array}{l}163.0395 \\
145.0279 \\
135.0454\end{array}$ & $\begin{array}{l}191.0549 \\
179.0341 \\
135.0449\end{array}$ & Prototype component \\
\hline 3 & 3.87 & - & 375.1287 & $\mathrm{C}_{16} \mathrm{H}_{24} \mathrm{O}_{10}$ & Isomer of loganic acid & - & $\begin{array}{l}213.0765 \\
169.0867 \\
151.0759\end{array}$ & Prototype component \\
\hline 4 & 4.20 & - & 375.1287 & & Loganic acid & - & $\begin{array}{l}213.0778 \\
169.0853 \\
151.0773\end{array}$ & Prototype component \\
\hline 5 & 4.24 & - & 353.0873 & $\mathrm{C}_{16} \mathrm{H}_{18} \mathrm{O}_{9}$ & 3-O-Caffeoylquinic acid & - & $\begin{array}{l}191.0569 \\
179.0365\end{array}$ & Prototype component \\
\hline 6 & 4.29 & - & 353.0873 & $\mathrm{C}_{16} \mathrm{H}_{18} \mathrm{O}_{9}$ & 4-O-Caffeoylquinic acid & - & $\begin{array}{l}173.0450 \\
135.0453\end{array}$ & Prototype component \\
\hline 7 & 4.37 & 478.1365 & - & $\mathrm{C}_{22} \mathrm{H}_{23} \mathrm{NO}_{11}$ & $\begin{array}{l}\text { Isorhamnetin } \\
\text { 7-glucosamine }\end{array}$ & $\begin{array}{l}316.0847 \\
298.0745 \\
280.0654\end{array}$ & - & $\begin{array}{l}\text { Metabolite of } \\
\text { flavonoids }\end{array}$ \\
\hline 8 & 4.42 & - & 475.1816 & $\mathrm{C}_{21} \mathrm{H}_{32} \mathrm{O}_{12}$ & Kanokoside A & - & $\begin{array}{l}313.0276 \\
193.0493 \\
123.0452\end{array}$ & Metabolite of iridoids \\
\hline 9 & 4.43 & 375.1288 & 373.1129 & $\mathrm{C}_{16} \mathrm{H}_{22} \mathrm{O}_{10}$ & Secologanic acid & $\begin{array}{l}213.0749 \\
195.0638\end{array}$ & $\begin{array}{l}193.0494 \\
149.0605\end{array}$ & Prototype component \\
\hline 10 & 4.45 & - & 389.1074 & $\mathrm{C}_{16} \mathrm{H}_{22} \mathrm{O}_{11}$ & Monotropein & - & 209.0455 & Prototype component \\
\hline 11 & 4.57 & - & 369.0815 & $\mathrm{C}_{16} \mathrm{H}_{18} \mathrm{O}_{10}$ & $\begin{array}{c}\text { Ferulic acid } \\
\text { 4-O-glucuronide }\end{array}$ & - & $\begin{array}{l}193.0490 \\
178.0263\end{array}$ & $\begin{array}{c}\text { Metabolite of quinic } \\
\text { acids }\end{array}$ \\
\hline 12 & 4.72 & - & 403.1239 & $\mathrm{C}_{17} \mathrm{H}_{24} \mathrm{O}_{11}$ & Isomer of secoxyloganin & - & 241.1177 & Prototype component \\
\hline 13 & 4.73 & 359.1348 & - & $\mathrm{C}_{16} \mathrm{H}_{22} \mathrm{O}_{9}$ & Sweroside & $\begin{array}{r}197.0812 \\
151.0400\end{array}$ & - & Prototype component \\
\hline 14 & 5.03 & - & 731.1866 & $\mathrm{C}_{31} \mathrm{H}_{40} \mathrm{O}_{18} \mathrm{~S}$ & $\begin{array}{l}\text { Methylated and sulfated } \\
\text { forsythiaside }\end{array}$ & - & $\begin{array}{l}651.2212 \\
457.1421\end{array}$ & $\begin{array}{c}\text { Metabolite of } \\
\text { phenylethanoid } \\
\text { glycosides }\end{array}$ \\
\hline 15 & 5.06 & 405.1387 & 403.1236 & $\mathrm{C}_{17} \mathrm{H}_{24} \mathrm{O}_{11}$ & Secoxyloganin & $\begin{array}{c}243.0880 \\
211.0612\end{array}$ & $\begin{array}{l}371.0979 \\
223.0611\end{array}$ & Prototype component \\
\hline 16 & 5.09 & - & 515.1174 & $\mathrm{C}_{25} \mathrm{H}_{24} \mathrm{O}_{12}$ & $\begin{array}{l}\text { 3,4-Dicaffeoylquinic } \\
\text { acid }\end{array}$ & - & $\begin{array}{c}353.0906 \\
191.0561 \\
135.0446\end{array}$ & Prototype component \\
\hline 17 & 5.16 & 623.1266 & 621.1092 & $\mathrm{C}_{27} \mathrm{H}_{26} \mathrm{O}_{17}$ & $\begin{array}{c}\text { Genistein } \\
4^{\prime}, 7-\mathrm{O} \text {-diglucuronide }\end{array}$ & $\begin{array}{l}447.0916 \\
271.0607\end{array}$ & $\begin{array}{c}445.0765 \\
357.1336 \\
269.0444\end{array}$ & $\begin{array}{l}\text { Metabolite of } \\
\text { flavonoids }\end{array}$ \\
\hline 18 & 5.20 & - & 827.2600 & $\mathrm{C}_{37} \mathrm{H}_{48} \mathrm{O}_{21}$ & $\begin{array}{c}\text { 2-(3,4- } \\
\text { Dihydroxyphenyl)ethyl6- } \\
\text { deoxy-mannopyranosyl- } \\
\text { glucopyranosyl-2-O-acetyl- } \\
\text { 4-O-[3-(3,4- } \\
\text { dihydroxyphenyl)-2- } \\
\text { propenoyl]- } \\
\text { glucopyranoside }\end{array}$ & - & $\begin{array}{l}520.1801 \\
429.1375 \\
437.0904\end{array}$ & $\begin{array}{l}\text { Metabolite of } \\
\text { phenylethanoid } \\
\text { glycosides }\end{array}$ \\
\hline 19 & 5.21 & - & 519.1863 & $\mathrm{C}_{26} \mathrm{H}_{32} \mathrm{O}_{11}$ & Pinoresinol 4-O-glucoside & - & $\begin{array}{l}357.1336 \\
151.0398 \\
136.0164\end{array}$ & Prototype component \\
\hline 20 & 5.47 & 623.1250 & 621.1088 & $\mathrm{C}_{27} \mathrm{H}_{26} \mathrm{O}_{17}$ & Baicalein 6,7-diglucuronide & $\begin{array}{l}447.0922 \\
271.0605\end{array}$ & $\begin{array}{l}445.0774 \\
269.0452\end{array}$ & $\begin{array}{l}\text { Metabolite of } \\
\text { flavonoids }\end{array}$ \\
\hline 21 & 5.54 & 609.1461 & 607.1299 & $\mathrm{C}_{27} \mathrm{H}_{28} \mathrm{O}_{16}$ & $\begin{array}{c}\text { Luteolin 7-glucuronide- } 4^{\prime} \text { - } \\
\text { rhamnoside }\end{array}$ & $\begin{array}{l}447.0919 \\
271.0610 \\
\end{array}$ & 431.0965 & $\begin{array}{l}\text { Metabolite of } \\
\text { flavonoids }\end{array}$ \\
\hline
\end{tabular}


TABLE 2: Continued.

\begin{tabular}{|c|c|c|c|c|c|c|c|c|}
\hline NO. & $t_{R}(\min )$ & $\begin{array}{l}\text { Positive } \\
\text { ion MS }\end{array}$ & $\begin{array}{l}\text { Negative } \\
\text { ion MS }\end{array}$ & Formula & Identification & $\begin{array}{l}\text { Positive } \\
\text { ion } \\
\text { MS/MS }\end{array}$ & $\begin{array}{l}\text { Negative } \\
\text { ion } \\
\text { MS/MS }\end{array}$ & Relegation \\
\hline 22 & 5.54 & - & 757.2550 & $\mathrm{C}_{34} \mathrm{H}_{46} \mathrm{O}_{19}$ & Centauroside & - & $\begin{array}{l}525.1569 \\
493.1695 \\
179.0511\end{array}$ & $\begin{array}{c}\text { Prototype } \\
\text { components }\end{array}$ \\
\hline 23 & 5.69 & - & 287.0234 & $\mathrm{C}_{11} \mathrm{H}_{12} \mathrm{O}_{7} \mathrm{~S}$ & $\begin{array}{c}5^{\prime}-\left(3^{\prime}, 4^{\prime}-\right. \\
\text { Dihydroxyphenyl)-gamma- } \\
\text { valerolactone sulfate }\end{array}$ & - & $\begin{array}{l}207.0651 \\
179.0334 \\
135.0437\end{array}$ & $\begin{array}{l}\text { Metabolite of } \\
\text { flavonoids }\end{array}$ \\
\hline 24 & 5.78 & - & 533.2020 & $\mathrm{C}_{27} \mathrm{H}_{34} \mathrm{O}_{11}$ & Phillyrin & - & $\begin{array}{l}371.1484 \\
356.1257 \\
121.0295\end{array}$ & Prototype component \\
\hline 25 & 5.88 & 447.0925 & 445.0771 & $\mathrm{C}_{21} \mathrm{H}_{18} \mathrm{O}_{11}$ & Baicalin & 271.0603 & $\begin{array}{l}269.0455 \\
241.0503\end{array}$ & Prototype component \\
\hline 26 & 6.17 & 431.0969 & 429.0815 & $\mathrm{C}_{21} \mathrm{H}_{18} \mathrm{O}_{10}$ & Chrysin 7-glucuronide & 255.0645 & 253.0505 & Prototype component \\
\hline 27 & 6.23 & 461.1079 & 459.0927 & $\mathrm{C}_{22} \mathrm{H}_{20} \mathrm{O}_{11}$ & Wogonoside & 285.0760 & $\begin{array}{l}283.0611 \\
268.0375 \\
239.0345\end{array}$ & Prototype component \\
\hline 28 & 6.38 & - & 445.0779 & $\mathrm{C}_{21} \mathrm{H}_{18} \mathrm{O}_{11}$ & $\begin{array}{l}\text { Norwogonin-7-O- } \\
\text { glucuronide }\end{array}$ & - & $\begin{array}{c}269.0449 \\
131.0625\end{array}$ & Prototype component \\
\hline 29 & 6.41 & - & 349.0014 & $\mathrm{C}_{15} \mathrm{H}_{10} \mathrm{O}_{8} \mathrm{~S}$ & Baicalein 7-sulfate & - & 269.0449 & $\begin{array}{l}\text { Metabolite of } \\
\text { flavonoids }\end{array}$ \\
\hline 30 & 6.43 & - & 363.0174 & $\mathrm{C}_{16} \mathrm{H}_{12} \mathrm{O}_{8} \mathrm{~S}$ & Wogonin 7-sulfate & - & 283.0606 & $\begin{array}{l}\text { Metabolite of } \\
\text { flavonoids }\end{array}$ \\
\hline 31 & 6.46 & - & 283.0607 & $\mathrm{C}_{16} \mathrm{H}_{12} \mathrm{O}_{5}$ & $\begin{array}{l}\text { 7,5-Dihydroxy-6- } \\
\text { methoxyflavone }\end{array}$ & - & 268.0371 & $\begin{array}{l}\text { Metabolite of } \\
\text { flavonoids }\end{array}$ \\
\hline 32 & 6.81 & 271.0608 & 269.0446 & $\mathrm{C}_{15} \mathrm{H}_{10} \mathrm{O}_{5}$ & Baicalein & $\begin{array}{l}271.0623 \\
253.0498 \\
123.0083\end{array}$ & $\begin{array}{l}251.0362 \\
223.0379 \\
195.0447\end{array}$ & Prototype component \\
\hline 33 & 7.26 & 285.0761 & 283.0602 & $\mathrm{C}_{16} \mathrm{H}_{12} \mathrm{O}_{5}$ & Wogonin & 270.0489 & $\begin{array}{l}268.0377 \\
162.9845\end{array}$ & Prototype component \\
\hline 34 & 7.35 & 255.0654 & - & $\mathrm{C}_{15} \mathrm{H}_{10} \mathrm{O}_{4}$ & Chrysin & 153.0173 & - & Prototype component \\
\hline 35 & 7.41 & 285.0761 & 283.0601 & $\mathrm{C}_{16} \mathrm{H}_{12} \mathrm{O}_{5}$ & Wogonin & 270.0502 & 268.0409 & Prototype component \\
\hline
\end{tabular}

data were processed using MarkerLynx XS to detect peaks and generate a three-dimensional data with $t_{R}-m / z$ pairs and the corresponding intensities. Statistical analysis by OPLS-DA was subsequently performed on the entire dataset. Figure 3 showed the OPLS-DA score plots of human serum samples before and after SHLI injection. Clear separation was observed between the two groups, which indicated that the drug-induced constituents were contributed to the clustering.

\subsection{Identification and Analysis of Prototype Components and} Metabolites. In order to discover the multiple prototype components and metabolites of SHLI in human serum, Splot, a tool for visualization and interpretation of multivariate classification models, was used. In the S-plot, each point represented an ion detected by UPLC-Q-TOF/MS. Variables that were the farthest from the origin in the S-plot were representative of the most significant changes between the two groups. Based on this, even subtle differences in the two groups could be easily extracted. Figure 4 showed the ions in
S-plot that were most responsible for distinguishing the $\mathrm{C}$ and SHLI groups and had a higher level in SHLI group.

The S-plot responsible for the variances in the data was a combination of metabolites derived from the SHLI administration and endogenous molecules which were ubiquitous to serum and were interfered by SHLI. From a drug metabolite identification perspective, it was important that the disturbance endogenous molecules could be eliminated, and the prototype components and metabolites could be easily screened between SHLI-treated group and the control group. This comparison was achieved by using the trend plot. From the trend plots, the variables that only existed in the dosed serums were marked as the prototype components or the metabolites of SHLI. Figure 5 showed the visualized trend plot of 7.41-285.0762 in positive mode between $\mathrm{C}$ group and SHLI group. The ion only appeared in the SHLI group. Therefore, 7.41285.0762 might be a prototype component or a metabolite of SHLI.

Based on the metabolomic strategy, 35 exogenous components in human serum were found, among them, 23 prototype 


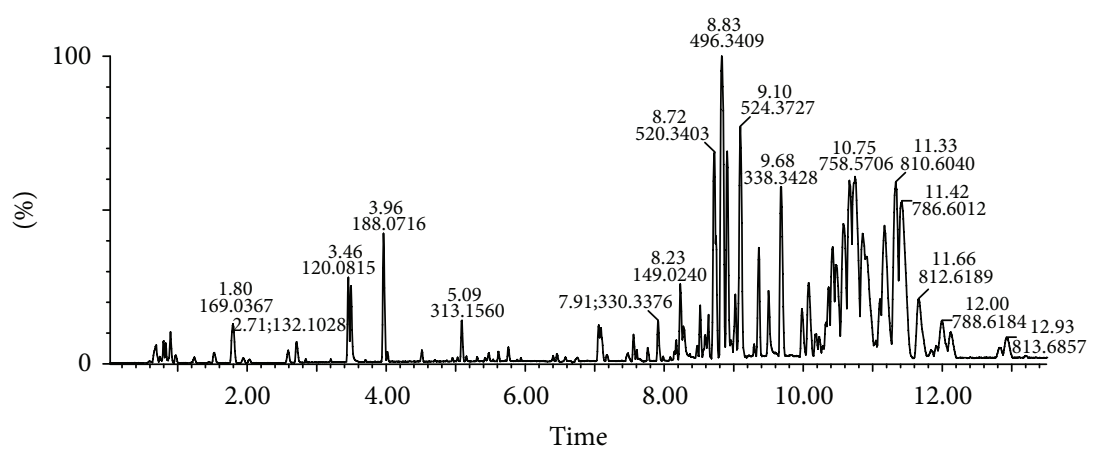

(a)

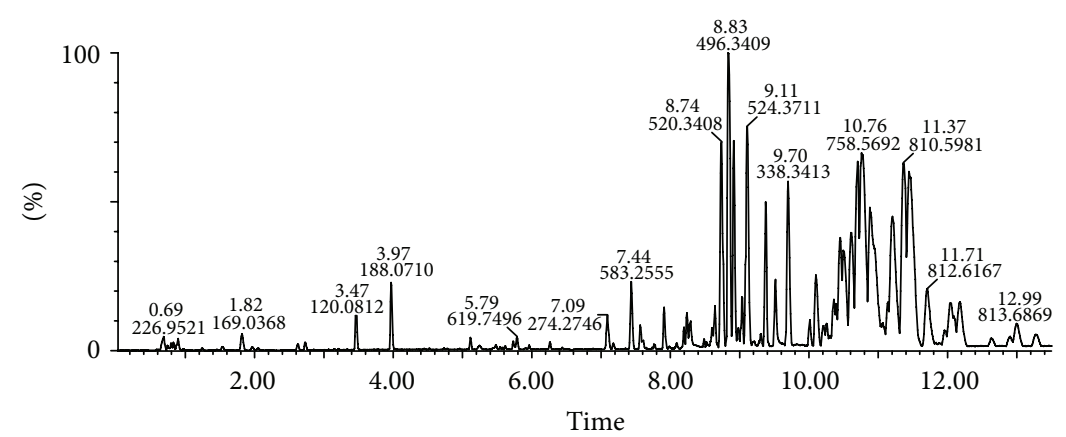

(b)

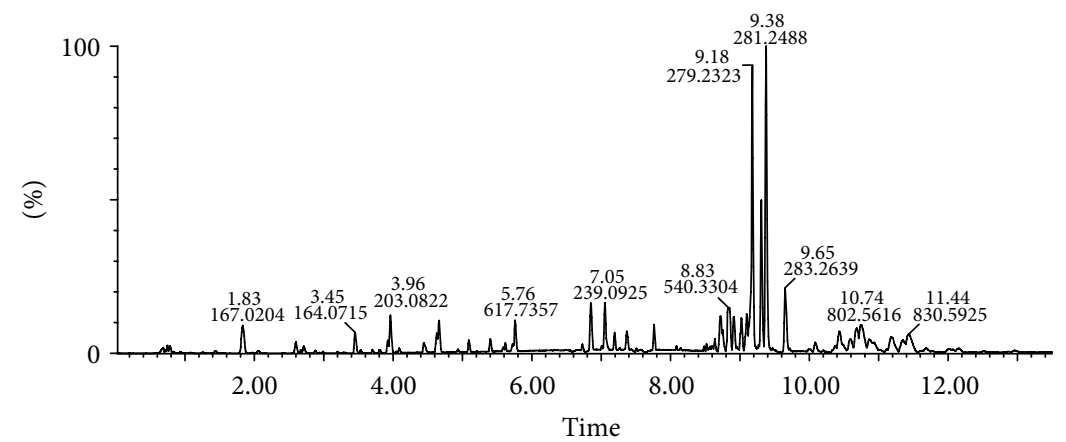

(c)

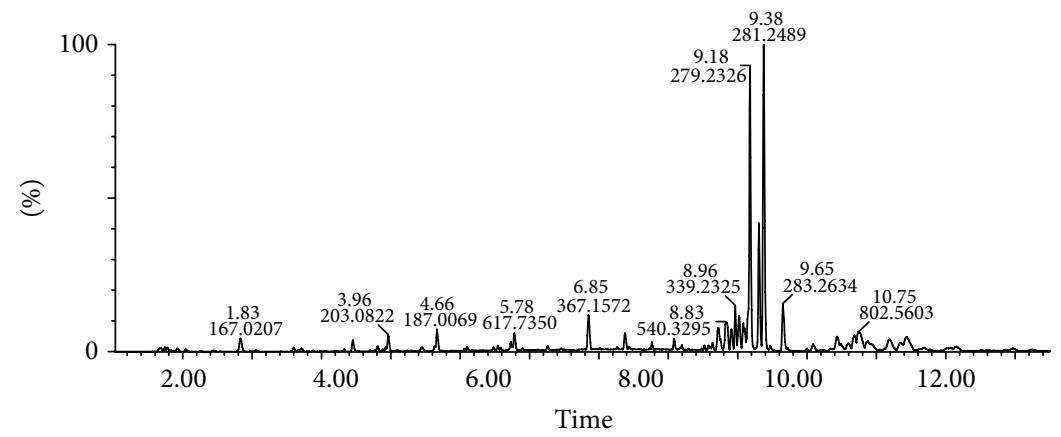

(d)

FIGURE 2: UPLC-Q-TOF/MS BPI chromatograms of human serum samples (a) before SHLI administration in positive ion mode, (b) after SHLI administration in positive ion mode, (c) before SHLI administration in negative ion mode, and (d) after SHLI administration in negative ion mode. 


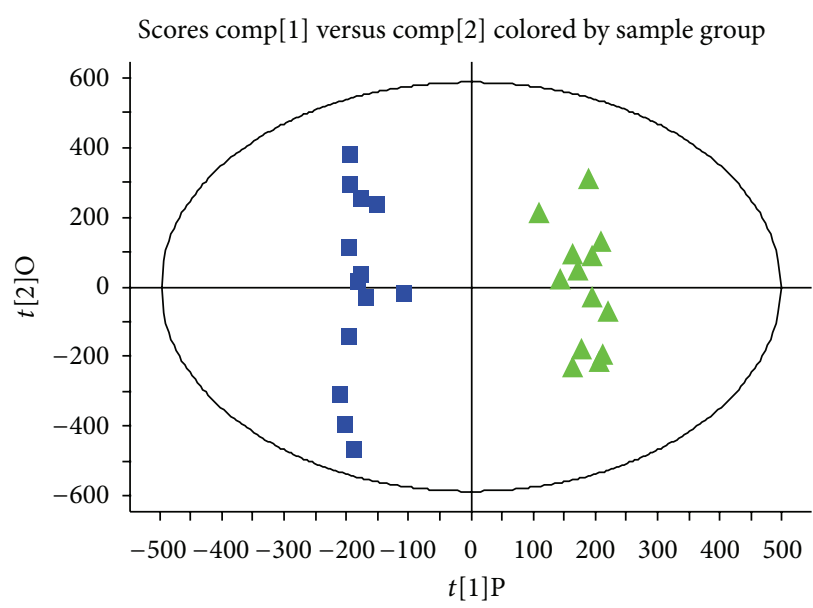

(a)

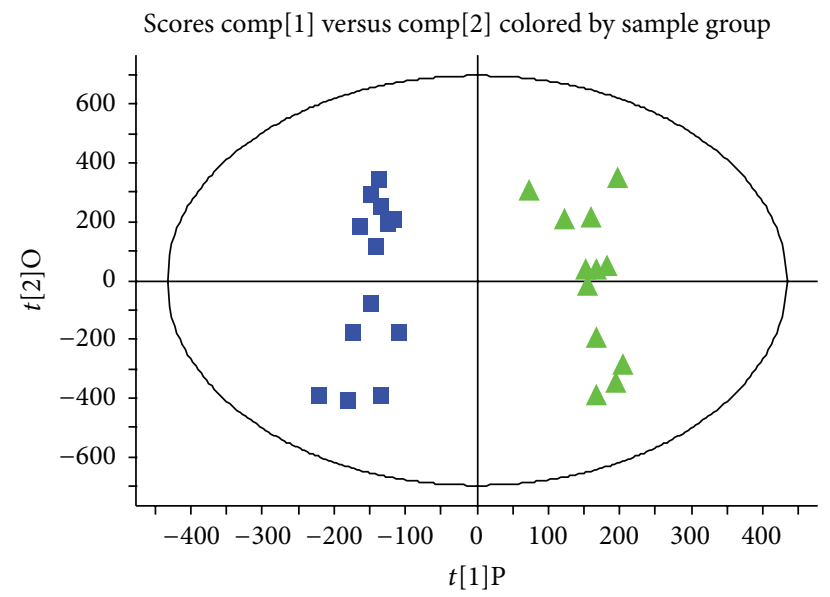

(b)

Figure 3: Score plots of OPLS-DA in human serum samples between C group ( $\mathbf{\square})$ and SHLI group (ム) in (a) positive ion mode and (b) negative ion mode.

S-Plot (group $1=-1$, group $2=1$ )

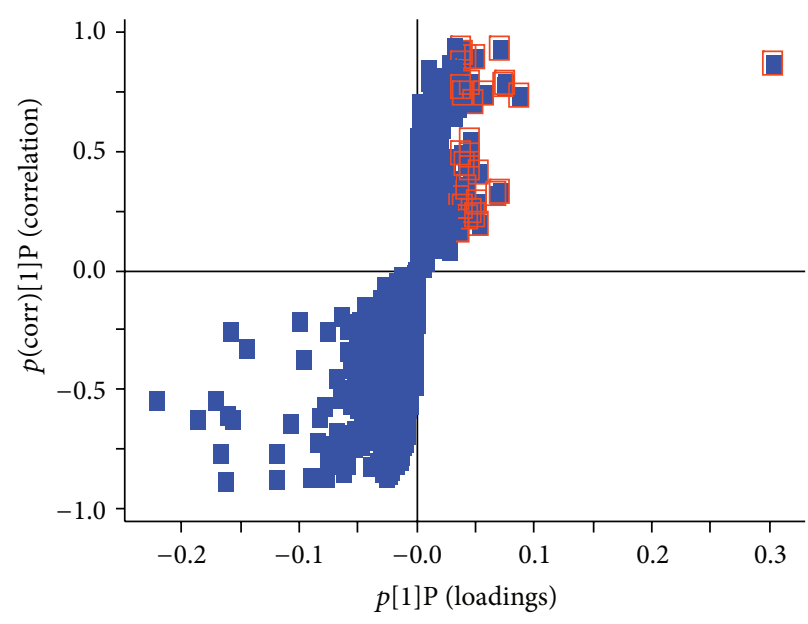

(a)

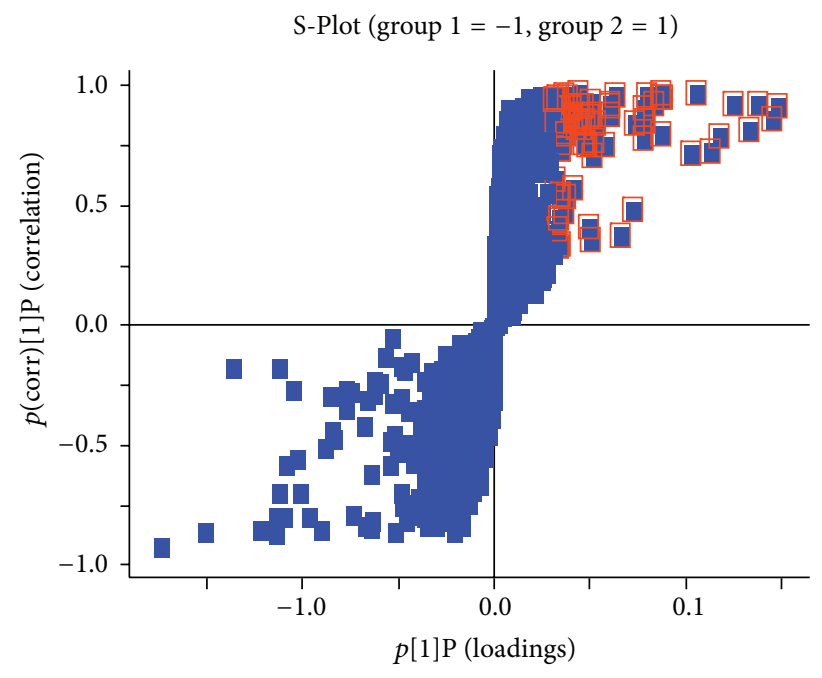

(b)

FIGURE 4: S-plots of human serum samples between C and SHLI groups in (a) positive ion mode and (b) negative ion mode. The ions marked with box were at the higher level in SHLI group.

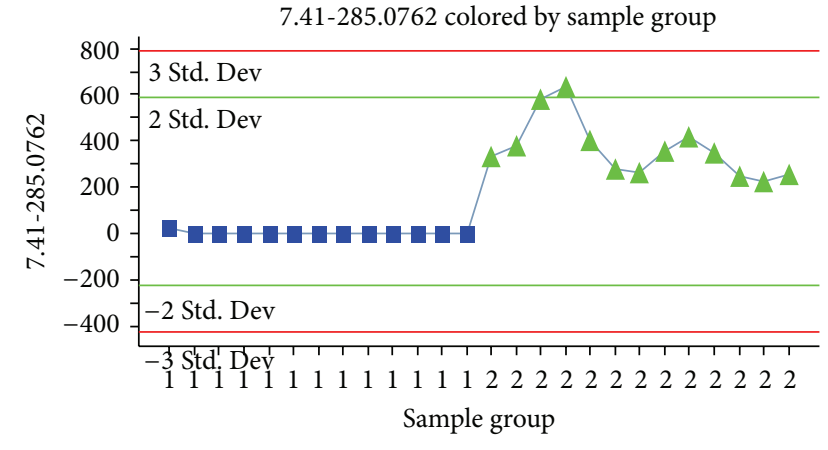

FIgURE 5: The trend plot of 7.41-285.0762 in positive mode between C group ( $\mathbf{\square})$ and SHLI group ( $\mathbf{\Delta})$. components of SHLI and 12 metabolites were identified and their information was shown in Table 2.

3.4. Characterization Analysis of Human Serum Prototype Components and Metabolites of SHLI. In our study, the prototype components and metabolites of SHLI were identified by comparing the accurate mass and $\mathrm{MS}^{\mathrm{E}}$ fragment information obtained from the $\mathrm{MS}^{\mathrm{E}}$ technique. Figure 6 showed typical MS/MS spectra of the prototype component 6.23-461.1079 and the flavonoid metabolite 6.46-363.0174. In positive ion mode, the ion at $m / z 483.0906$ was $[\mathrm{M}+\mathrm{Na}]^{+}$ion. The dominant fragment ion of $\mathrm{m} / z 285.0763$ was produced by loss of $m / z 176$ (glucuronide- $\mathrm{H}_{2} \mathrm{O}$ ) fragment from $[\mathrm{M}+$ $\mathrm{H}]^{+}$in positive ion mode. The characteristic and abundant 


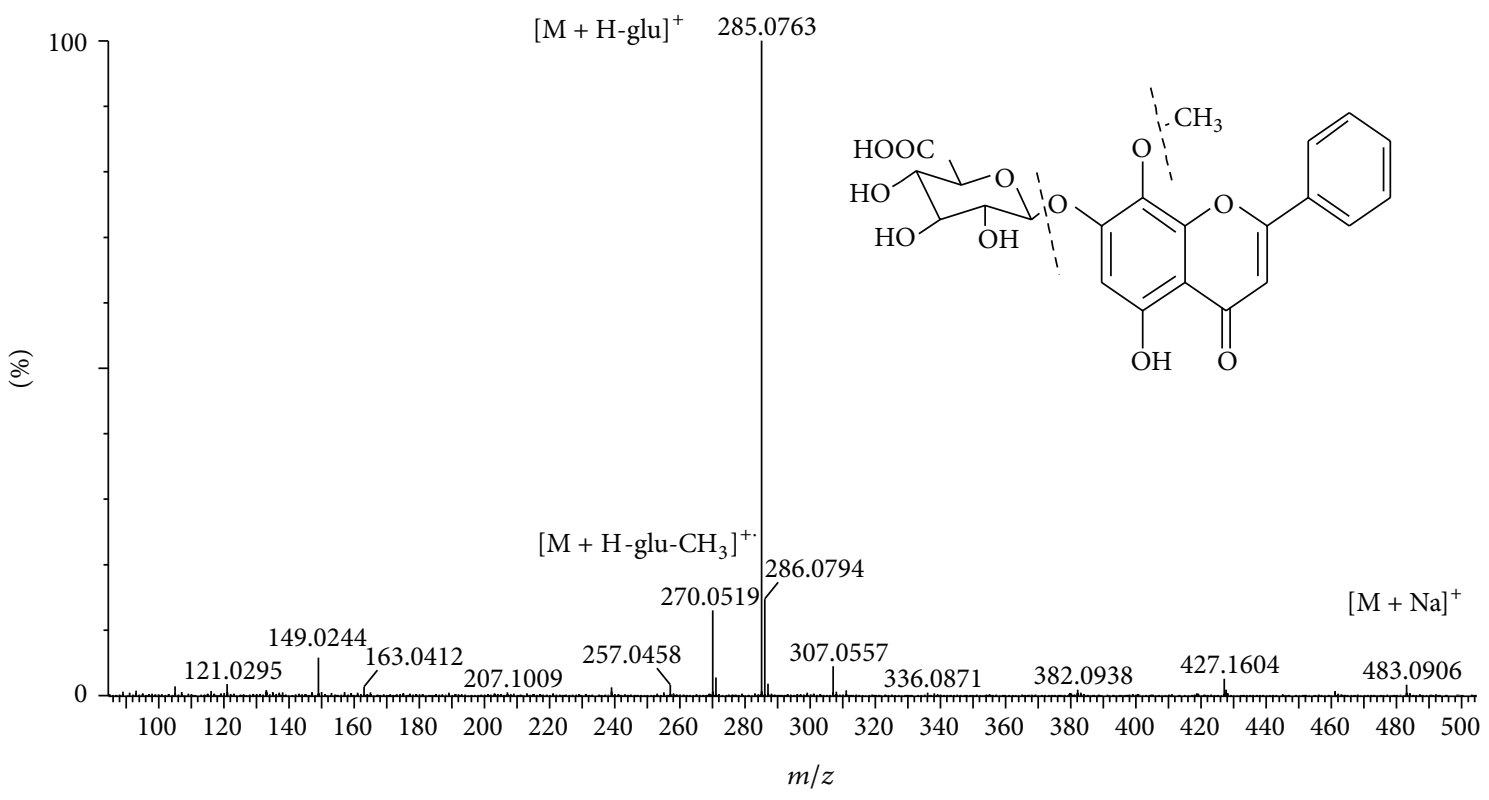

(a)

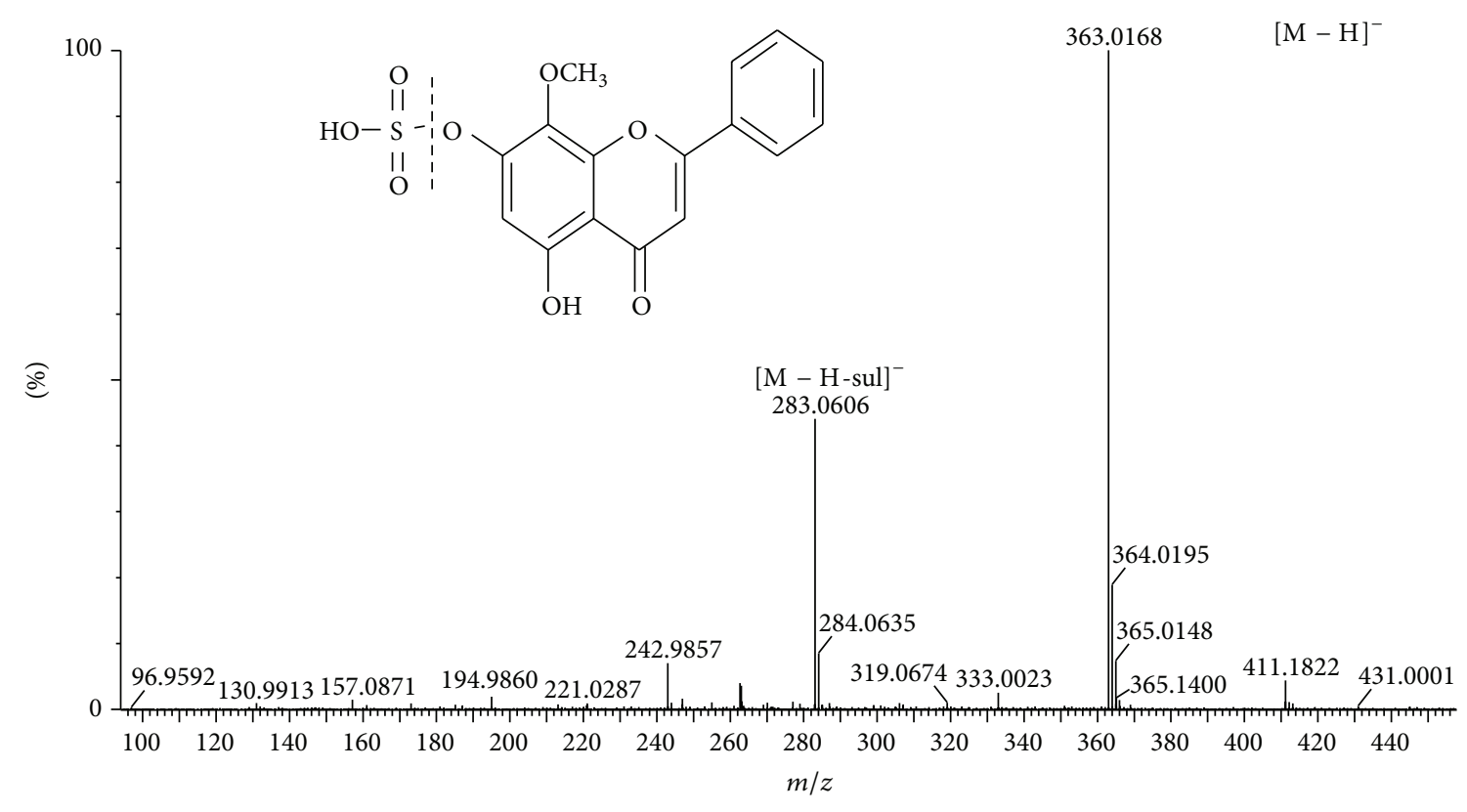

(b)

FIGURE 6: MS/MS spectra and structures of (a) prototype compound wogonoside in positive ion mode and (b) flavonoids metabolite wogonin 7-sulfate in negative ion mode identified in human serum after $\mathrm{SHLI}$ administration. In the tag, glu was the abbreviation of glucuronide- $\mathrm{H}_{2} \mathrm{O}$ and sul was the abbreviation of sulfate- $\mathrm{H}_{2} \mathrm{O}$.

fragment ion $\left[\mathrm{M}+\mathrm{H}-\mathrm{CH}_{3}\right]^{+\bullet}$ was generated by loss of $\mathrm{CH}_{3}^{\bullet}$ for the flavones with a methoxyl group on the side chains of an aromatic ring. Its molecular formula was speculated to be $\mathrm{C}_{22} \mathrm{H}_{21} \mathrm{O}_{11}$ based on the analysis of its elemental composition. Then the ion at $m / z 483.0906$ was inferred as wogonoside. The ion at $m / z 363.0168$ was $[\mathrm{M}-\mathrm{H}]^{-}$ion. The major fragment ion of $\mathrm{m} / z 283.0606$ was generated by loss of $m / z 80$ (sulfate- $\mathrm{H}_{2} \mathrm{O}$ ) fragment from $[\mathrm{M}-\mathrm{H}]^{-}$in negative ion mode. The molecular formula was speculated to be $\mathrm{C}_{16} \mathrm{H}_{12} \mathrm{O}_{8} \mathrm{~S}$, and the fragmentation information and the molecular formula were consistent with wogonin 7-sulfate. Other metabolites were determined by the same method described above and some of them were also supported by the databases such as HMDB (http://www.hmdb.ca/) and METLIN (http://masspec.scripps.edu/). As a result, 23 prototype components and 12 metabolites of SHLI were identified. 
3.5. Correlative Analysis of the Prototype Components and Metabolites of SHLI. The prototype herb components could be further metabolized by various drug metabolizing enzymes. Drug metabolism is classified into phase I and phase II reactions. Phase I reactions are mediated primarily by the cytochrome P450 family of microsomal enzymes [25]. Compounds are factionalized by oxidation, hydrolysis, or reduction, leading to the introduction of, for example, hydroxyl, amino, carboxyl, or thiol groups into the molecule. Most compounds undergo phase I oxidation prior to phase II conjugation, but molecules with sites amenable to conjugation may undergo phase II reactions directly. The most relevant phase II drug conjugation reactions are methylation, sulfation, glucuronidation, and glutathione conjugation. There were three types of components found in human serum after SHLI administration: (i) compounds found in their native form; (ii) phase I metabolites formed by chemical modifications, such as hydroxylation $(\mathrm{M}+\mathrm{OH})$ and hydration $\left(\mathrm{M}+\mathrm{H}_{2} \mathrm{O}\right)$, and (iii) phase II metabolites formed by conjugation, such as methylation $\left(\mathrm{M}+\mathrm{CH}_{3}\right)$, glucuronidation $\left(\mathrm{M}+\mathrm{C}_{6} \mathrm{H}_{8} \mathrm{O}_{6}\right)$, sulfation $\left(\mathrm{M}+\mathrm{HSO}_{3}\right)$, and other conjugation reactions. In human serum, a large number of phase II metabolites were found. Among them, 8 flavonoids metabolites, 2 phenylephrine glycosides metabolites, 1 iridoid metabolite, and 1 quinic acid metabolite were found.

Some researchers have reported the metabolites of SHL formula in rat plasma [8]. We compared the metabolites differences in human and rats after SHLI administration and found great differences on the types and quantities of the metabolites after SHLI or SHL formula administrated between human and rats. The metabolites of SHLI found in rats and human were listed in Supplementary Material (see Table S1 in Supplementary Material available online at http://dx.doi.org/10.1155/2014/241505). Large number of phase I metabolites were detected in rats such as dihydrosecologanic acid and 3,4-dihydroxyphenylethanol, while little was found in the human serum. Besides, sulfated metabolites which were common in human serum were less detected in the rat plasma. Such a discrepancy might be attributed to different species (human or rats), prescription (SHLI or SHL formula), or blood collection time ( $1 \mathrm{~h}$ or shorter time). Further studies of the biological properties of these metabolites would be helpful to understand the pharmacological mechanism of SHLI.

\section{Conclusion}

In this paper, we developed an unbiased approach for screening the prototype components and metabolites of SHLI in human serum based on metabolomic technique. Employing UPLC-Q-TOF-MS combined with multivariate statistical analysis, 23 prototype components and 12 metabolites of SHLI were rapidly and sensitively identified, which suggested that the metabolomic approach was an effective tool to discover, screen, and analyze the multiple prototype components and metabolites from complicated traditional Chinese preparations in vivo. SHLI in human body mainly caused phase II metabolite reactions such as sulfation, methylation, glucuronidation, and other complex conjugation reactions. This identification and structural elucidation of the chemical compounds provided essential data for further pharmacological and pharmacokinetics study of SHLI. The human serum metabolomic approach avoids the laborious process of predicting possible metabolites and provides information on unexpected reactive metabolites and a type of validated rapid and higher throughput methodology for the identification of constituents of traditional Chinese medicine.

\section{Conflict of Interests}

The authors declare that they have no conflict of interests regarding the publication of this paper.

\section{Acknowledgments}

This work was supported in part by National Science and Technology Major Projects for "Major New Drugs Innovation and Development" (Grant no. 2011ZX09201-201-15), National Science Foundation of China (Grant no. 81173562), and in part by the Foundation of Independent Topics at Beijing University of Chinese Medicine (Grant no. 2013-JYBZZ-XS064).

\section{References}

[1] H. Zhang, Q. Chen, W. Zhou et al., "Chinese medicine injection Shuanghuanglian for treatment of acute upper respiratory tract infection: a systematic review of randomized controlled trials," Evidence-Based Complementary and Alternative Medicine, vol. 2013, Article ID 987326, 7 pages, 2013.

[2] Y. Cao, L. Wang, X. Yu, and J. Ye, "Development of the chromatographic fingerprint of herbal preparations Shuang-HuangLian oral liquid," Journal of Pharmaceutical and Biomedical Analysis, vol. 41, no. 3, pp. 845-856, 2006.

[3] The State Commission of Chinese Pharmacopoeia, Pharmacopoeia of People's Republic of China, part 1, Chemical Industry Press, Beijing, China, 2005.

[4] Y. M. Zhang, D. Yan, P. Zhang et al., "Quality control of Shuanghuanglian freeze-dried powder for injection based on its HPLC-ELSD fingerprints and biological profiles," Acta Pharmaceutica Sinica, vol. 45, no. 1, pp. 93-97, 2010.

[5] L. Liu, Z. Suo, and J. Zheng, "Simultaneous determination of four compounds in Sanjing Shuanghuanglian oral liquid by high performance liquid chromatography-diode array detection-electrochemical detection," Chinese Journal of Chromatography, vol. 24, no. 3, pp. 247-250, 2006.

[6] H. Cao and Y. Zhu, "Content determination of chlorogenic acid and baicalin in Shuanghuanglian oral solution by HPLC," Drug Stands in China, vol. 8, no. 2, pp. 44-46, 2007.

[7] G. L. Yan, A. H. Zhang, H. Sun et al., "An effective method for determining the ingredients of Shuanghuanglian formula in blood samples using high-resolution LC-MS coupled with background subtraction and a multiple data processing approach," Journal of Separation Science, vol. 36, no. 19, pp. 31913199, 2013.

[8] M. J. Zamek-Gliszczynski, K. A. Hoffmaster, K. I. Nezasa, M. N. Tallman, and K. L. R. Brouwer, "Integration of hepatic drug 
transporters and phase II metabolizing enzymes: mechanisms of hepatic excretion of sulfate, glucuronide, and glutathione metabolites," European Journal of Pharmaceutical Sciences, vol. 27, no. 5, pp. 447-486, 2006.

[9] H. Ishizuka, K. Konno, T. Shiina et al., "Species differences in the transport activity for organic anions across the bile canalicular membrane," Journal of Pharmacology and Experimental Therapeutics, vol. 290, no. 3, pp. 1324-1330, 1999.

[10] G. B. Scarfe, J. C. Lindon, J. K. Nicholson et al., "Investigation of the metabolism of 14C/13C-practolol in rat using directly coupled radio-HPLC-NMR-MS," Xenobiotica, vol. 30, no. 7, pp. 717-729, 2000.

[11] J. Iwabu, J. Watanabe, K. Hirakura, Y. Ozaki, and K. Hanazaki, "Profiling of the compounds absorbed in human plasma and urine after oral administration of a traditional Japanese (Kampo) medicine, daikenchuto," Drug Metabolism and Disposition, vol. 38, no. 11, pp. 2040-2048, 2010.

[12] I. Iswaldi, D. Arráez-Román, A. M. Gómez-Caravaca et al., "Identification of polyphenols and their metabolites in human urine after cranberry-syrup consumption," Food and Chemical Toxicology, vol. 55, pp. 484-492, 2013.

[13] G. Tan, W. Liao, X. Dong et al., "Metabonomic profiles delineate the effect of traditional Chinese medicine Sini decoction on myocardial infarction in rats," PLoS ONE, vol. 7, no. 4, Article ID e34157, 2012.

[14] O. Corcoran and M. Spraul, "LC-NMR-MS in drug discovery," Drug Discovery Today, vol. 8, no. 14, pp. 624-631, 2003.

[15] M. S. Lee and E. H. Kerns, "LC/MS applications in drug development," Mass Spectrometry Reviews, vol. 18, no. 3-4, pp. 187-279, 1999.

[16] Y. Wu, "The use of liquid chromatography-mass spectrometry for the identification of drug degradation products in pharmaceutical formulations," Biomedical Chromatography, vol. 14, no. 6, pp. 384-396, 2000.

[17] X. Wang, W. Sun, H. Sun et al., "Analysis of the constituents in the rat plasma after oral administration of Yin Chen Hao Tang by UPLC/Q-TOF-MS/MS," Journal of Pharmaceutical and Biomedical Analysis, vol. 46, no. 3, pp. 477-490, 2008.

[18] S. L. Li, S. F. Lai, J. Z. Song et al., "Decocting-induced chemical transformations and global quality of Du-Shen-Tang, the decoction of ginseng evaluated by UPLC-Q-TOF-MS/MS based chemical profiling approach," Journal of Pharmaceutical and Biomedical Analysis, vol. 53, no. 4, pp. 946-957, 2010.

[19] L. Li, G. A. Luo, Q. L. Liang, P. Hu, and Y. M. Wang, "Rapid qualitative and quantitative analyses of Asian ginseng in adulterated American ginseng preparations by UPLC/Q-TOFMS," Journal of Pharmaceutical and Biomedical Analysis, vol. 52, no. 1, pp. 66-72, 2010.

[20] C. Chen, F. J. Gonzalez, and J. R. Idle, "LC-MS-based metabolomics in drug metabolism," Drug Metabolism Reviews, vol. 39, no. 2-3, pp. 581-597, 2007.

[21] Y. Y. Zhao, X. L. Cheng, F. Wei, X. Bai, and R. C. Lin, "Application of faecal metabonomics on an experimental model of tubulointerstitial fibrosis by ultra performance liquid chromatography/high-sensitivity mass spectrometry with $\mathrm{MS}^{\mathrm{E}}$ data collection technique," Biomarkers, vol. 17, no. 8, pp. 72217729, 2012.

[22] P. D. Rainville, C. L. Stumpf, J. P. Shockcor, R. S. Plumb, and J. K. Nicholson, "Novel application of reversed-phase UPLCoaTOF-MS for lipid analysis in complex biological mixtures: a new tool for lipidomics," Journal of Proteome Research, vol. 6, no. 2, pp. 552-558, 2007.
[23] J. Han, M. Ye, H. Guo, M. Yang, B. R. Wang, and D. A. Guo, "Analysis of multiple constituents in a Chinese herbal preparation Shuang-Huang-Lian oral liquid by HPLC-DADESI-MSn," Journal of Pharmaceutical and Biomedical Analysis, vol. 44, no. 2, pp. 430-438, 2007.

[24] Q. Z. Luo, J. B. Luo, and Y. Z. Wang, "Qualitative analysis of the main chemical constituents of Shuanghuanglian injection powder and their origin by HPLC-ESI/MS/MS spectrometry," Acta Pharmaceutica Sinica, vol. 44, no. 12, pp. 1391-1396, 2009.

[25] M. J. Zamek-Gliszczynski, K. A. Hoffmaster, K. I. Nezasa, M. N. Tallman, and K. L. R. Brouwer, "Integration of hepatic drug transporters and phase II metabolizing enzymes: mechanisms of hepatic excretion of sulfate, glucuronide, and glutathione metabolites," European Journal of Pharmaceutical Sciences, vol. 27, no. 5, pp. 447-486, 2006. 

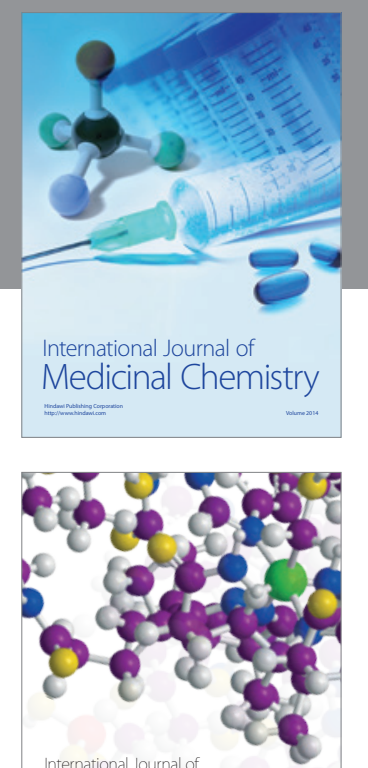

\section{Carbohydrate} Chemistry

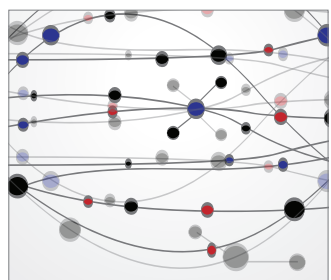

The Scientific World Journal
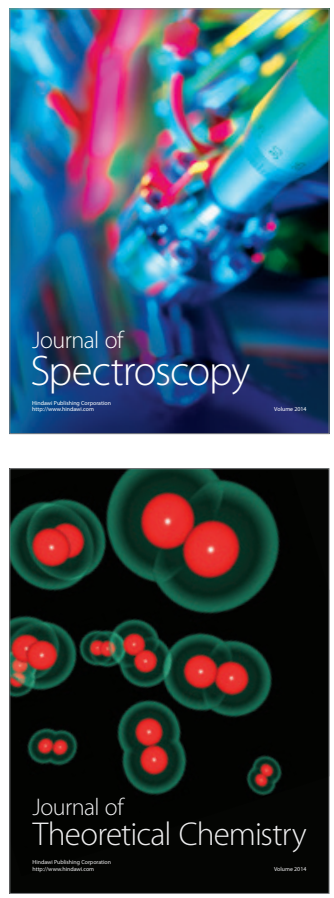
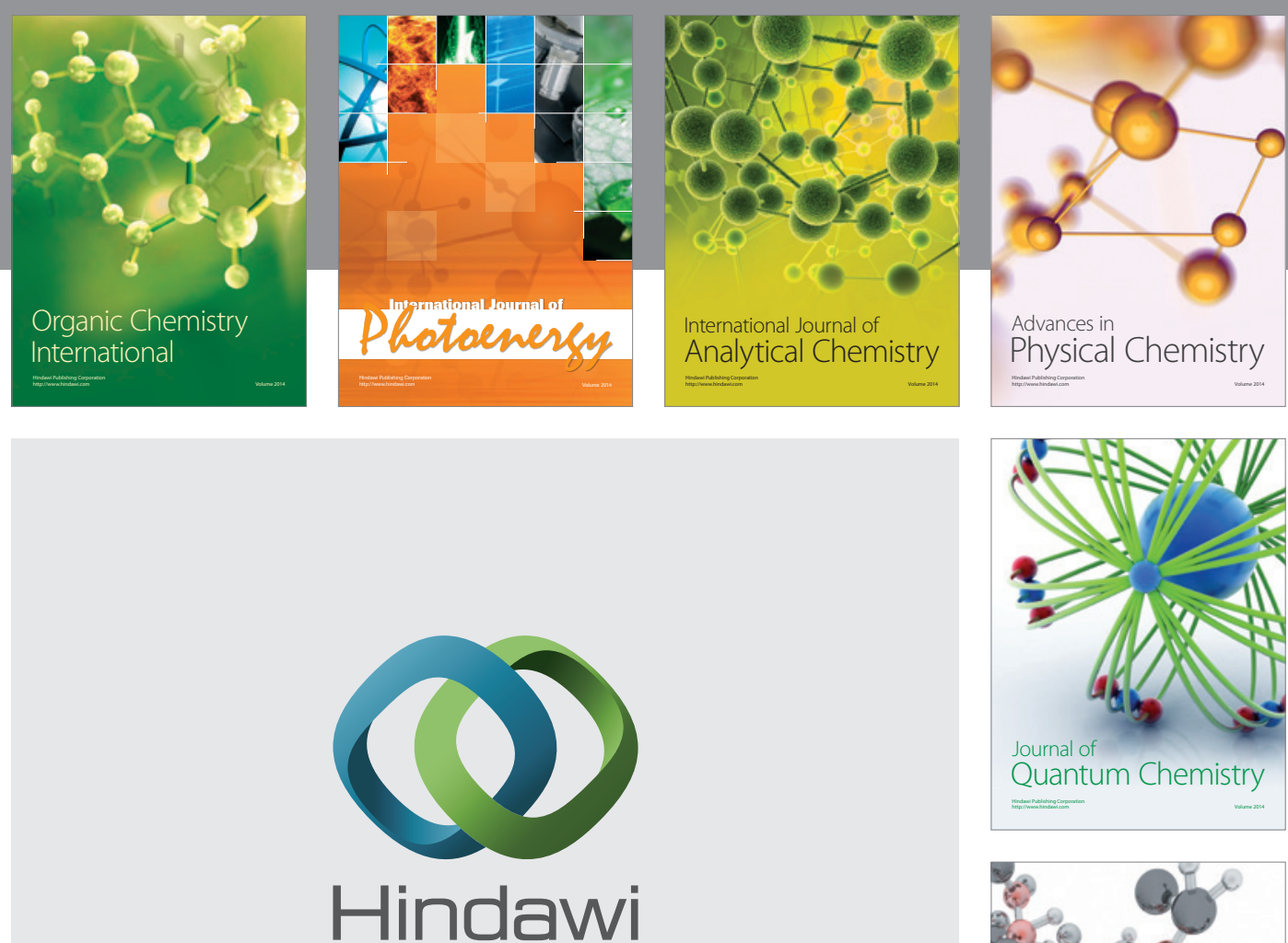

Submit your manuscripts at

http://www.hindawi.com

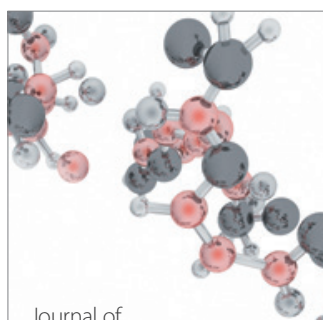

Analytical Methods

in Chemistry

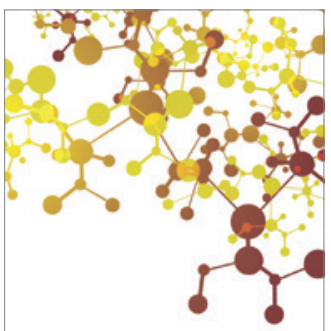

Journal of

Applied Chemistry

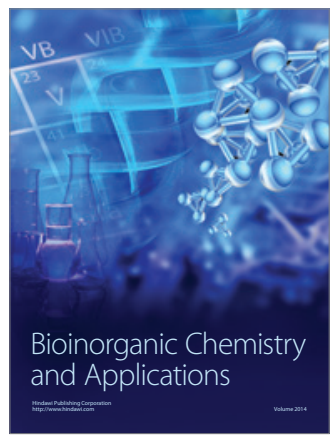

Inorganic Chemistry
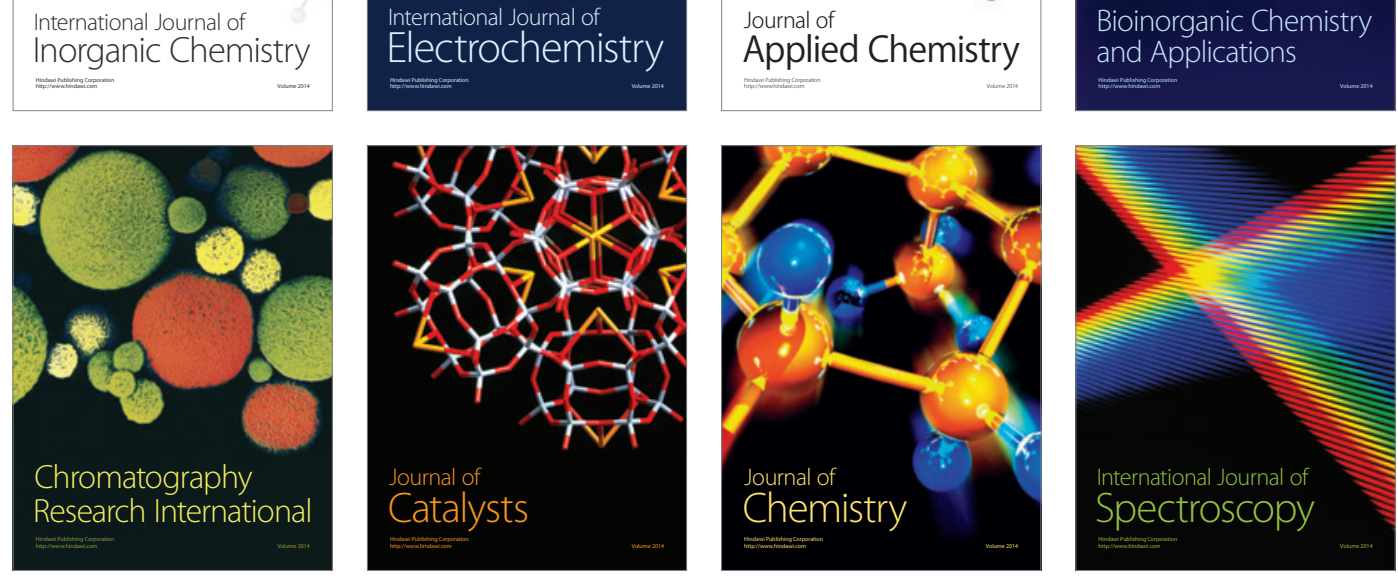